\title{
Environment friendly management of mosquito: a short review
}

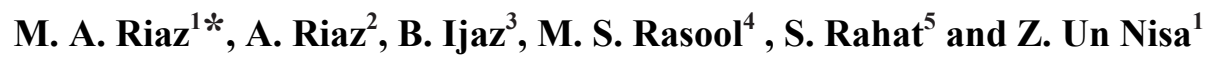 \\ ${ }^{I}$ Department of Environmental Sciences \& Engineering, Government College University Faisalabad, Pakistan \\ ${ }^{2}$ Department of Zoology, Government College Women University, Faisalabad, Pakistan \\ ${ }^{3}$ Environmental Sciences, Sustainable Development Study Centre, Government College University, Lahore, Pakistan \\ ${ }^{4}$ Department of Environmental Management, National College of Business Administration \& Economics, Lahore, Pakistan \\ ${ }^{5}$ College of Earth and Environmental Science, Quaid-e-Azam Campus, University of the Punjab, Lahore, Pakistan
}

Received: 06 August 2017

Revised: 27 September 2017

Accepted: 31 January 2018

DOI: http://dx.doi.org/10.3329/bjsir.v53i3.38262

\begin{abstract}
Despite the large scale use of insecticides, capacity building, municipality, community and metropolis awareness, and preventive measures to counter vector borne diseases which are mounting day-by-day, new tools are now been introducing to prevent the spread of mosquito transmitted diseases. The low efficacy status of chemical pesticides have lead to the interest of researchers in search of fresh and even more practicable vector control methodologies to be applied. In this regards, multiple alternatives have been monitoring to develop control practice measures for the eradication, observation and control of mosquitoes at larval level by the use of a sustainable biological monitoring and control by an ordinary constructive predator, to exercise monitoring and practical control measures over parasites at larval stages in environmental and eco-friendly techniques. In particular, bio-control measures to monitor and control practical practices, context predatory larvivorous fish, dragonfly nymph, frogs, copepods, turtle, Entomopathogenic bacillus, Bacillus sphaericus and Bacillus thuringiensis israelensis are beings tried in different regions of world. The available research on the subject recommends that there exist multiple direct and indirect growth factors that could play a dynamic role in prey and predator's survival. Species controphic that have an impact on concerned eco-relation reflect significant effect. In addition to this, certain eco-relations represent positive stimuli for the control of vector borne viral diseases. As a bio-control achieving feasible agent for vector monitoring, pointing, management and control predatory larvivorous fish, dragonfly nymph, frogs, copepods, turtle, Entomopathogenic bacillus, Bacillus sphaericus and Bacillus thuringiensis israelensis are not only considered as a liberated intervention for disease vector control of practices and mechanical control cost deterrents as well. Further research has been suggested on the subject so as to find out even more practicable and effective mosquito monitoring and practical control practices..
\end{abstract}

Keyword: Mosquito-borne diseases; Environmental health; Copepods; Larvivorous fishes; Biological control; Health risk; Tadpole

\section{Introduction}

Public health risk expected to vector-borne pathogens pose a serious threat, resulting in the current era occurred about $30 \%$ of the disease burden (Huang et al., 2017). Chikungunya CHIKV; genus Alphavirus Zika ZIKV; genus Flavivirus and dengue DENV; genus Flavivirus and yellow fever viruses are spread by Aedes aegypti mosquitoes as disease vector and continue seen in some regions, the probability of infection by multiple mosquitoes borne viruses disease trend increasing (Baldacchino et al., 2017). Mosquitoes not only occupy certain niches, they are scattered around the world, and even in high temperature affected areas are affected by rainfall temperature, humidity and sea level (Gama and Nakagoshi., 2013; Wu et al., 2016). Natural climatic conditions are important factors in the distribution of different disease vectors (Dom et al., 2013; Mohiddin et al., 2016). 
Mosquito borne disease transmission is particularly sensitive to host factors including human community and behavior intervention measures, environmental and climatic conditions (Malik et al., 2017). In spite of modern monitoring and practical control practices, the mosquitoes population is increasing day after day all over the world. In contemporary world the male populations of mosquitoes are heritably sterilized. They used to mate with mature mosquito eggs. However, female population of mosquitoes lay sterilized mature eggs that are reported unable to hatch. Rather than decreasing, the population of vector carrying mosquitoes is increasing. Though, a number of states have had practiced the decontamination and spray on regularly basis. But, due to either the monitoring and practical control practices ling methods showed low efficacy for quite a short term, or very substantially cultured, unproductive or productive for some stage or very less significant and costly. Such as application of vector resistant spray is expensive, laborious, short term, short time, only effective for certain stage life style of mosquito's population and time taking. Indoor residual spray IRS is infrequently done when population of mosquitoes escalates and risk of emerging outbreaks threatened. Previously, the breeding sites of such vector carrying mosquito habitats were unknown. Therefore, the use of resistant sprays was more of a reactive than preventive action as it can de-activate adult population of mosquitoes (Tariq and Qadri, 2008; Santos and Meneses, 2017) but source of them remain intent and positive (Tariq, 2001; George et al., 2017). Aedes aegypti mosquitoes lay eggs in a variety of containers, is considered to be the domesticated mosquitoes, found crowded neighborhood in an urban environment (Harinder et al., 2014; Sutherst, 2004; Bandyopadhyay and Skoufias, 2015). Vector-borne diseases develop very close coordination in urban areas to adapt to the environment, population and intensive moisture, global warming (Hafeez et al., 2017; Malik et al., 2017; Chaudhry et al., 2017).

Insecticide resistance increasing in mosquito's biocontrol better program and public mobilization and community participation are considered to be basic tool to control disease transmission and controlling vector breeding (Dieng et al., 2011; Naqvi et al., 2015; Bouzid et al., 2016). In this way, such chemical sprays become ineffective rather, they immune the mosquito system as well. For this, importance should be specified to such monitoring and practical control measures which may be extended a bit longer than the previous one, and may prove to be effective, targeted, less time consuming, low charge and cost-friendly (Qadri et al., 2007). Bio-control is a best provided alternatives for incapacitating the insecticidal resistance resulting from the indiscriminate use of chemical substances and their destructive impacts on the environment. Bio monitoring and practical control methods are better due to safety, particularly for human being (Lacey, 2007; Terbot et al., 2015). Application of Fish copepods, plankton pointing, management and controlling (Ritchie, 2005; Ritchie et al., 2010; Ghosh et al,. 2011) have been verified as bio control agents in developing, and immature stages of the $A$. aegypti and 'A. albopictus' mosquitoes. Most monitoring and control agents are effective comparatively nontoxic, economically viable and are moderately tranquil to manage on a comprehensive and suitable to the targeted vector carrying mosquito population (Lacey, 2007; Diallo et al., 2016). Standing water basins and waste water stabilization pond water in the remote areas and, drains and open fresh water store tanks in the big cities are stimulating possible risk of mosquito caused infections and respectively dengue and malarial epidemic occurred in the municipality, rural community and metropolis population (Fatima et al., 2016; Atique et al., 2016; Malik et al., 2017).

Repeated practical practices applied for synthetic insecticides for mosquito monitoring and control practical practices has disrupted natural biological monitoring and control practice systems and led to resurgence in mosquito populations (Thomas, 2017). It has also stemmed in the improvement of insecticide immunization in mosquitoes which produced detrimental impacts on untargeted organisms and nurtured environmental, ecological, and human health concerns, initiating a search for alternative monitoring and control practical practices and measures. Pointing, management and controlling of mosquito emergent undeveloped and immature through biological monitoring and control practical practices is being tried world over (Kumar and Hwange, 2006; Manilal et al., 2011).

\section{Predatory larvivorous fish}

In fresh water bodies predatory larvivorous fish considers as best technique of larva monitoring and control practices in fresh water bodies. The mouth spot is of prior feature to determine the larvivorous competency of a fish. As of the tactic of their effectiveness in monitoring and control measuring mosquito larvae, Hora and Mukherjee (1953) classified the predatory larvivorous fish into the different categories as typical surface feeders, sub-surface feeders and column feeders. In 2002, Martinez and co-workers conducted research studies in Southern Mexico and described five local, indigenous and native fish species, namely Bryconguatemalensis, Lepisosteustropicus, Astyanaxfasciatus, P.reticulate and Ictalurusmeridionalis to be operative in contrast to and in contradiction of $A$. aegypti larvae in water reservoirs. Chandra et al. (2008) directed a research and described forty-four species the efficacy of $X$. cancila as bio monitoring and practical control practices 
agent contrary to and in contradiction of fourth stage larval form of Ar.subalbatus Cx. Quinquefasciatus and An. Subpictusunder laboratory settings. O. Mossambica were proved to be considerably effective for monitoring and control practices as in mosquitoes in cow manure pits in contradiction of $3^{\text {rd }}$ and $4^{\text {th }}$ instars larvae and even pupae of An. Culicifacies and Cx. Quinquefasciatus at the place of 5 fish sqm ${ }^{2}$ surface area. To obtain great development per-ha of aquatic frame, rapidly increasing compatible fish species of diverse nurturing practices and multiple mass figure of the concerned species are carried in the identical pools so that all its ecological population are scaled in categorized fish order. This structure of pool marking, management and controlling is called poly-culture or composite fish culture or mixed fish farming. On natural habitats (Ghosh et al., 2004) conducted research studies and described 50 species that predation experiment using C. carpio Ctenopharyngdonidella, $O$. niloticus and Clariasgariepinus were conducted against and in contradiction of fourth instar An. stephensi larvae.

Aditya et al. (2012) studied indigenous larvivorous fishes implications for biological control against Culex quinquefasciatus and found reduceding numbers of larva time to time. Similarly, Gupta and Banerjee (2013) had done a comparative experiment to check mosquito biocontrol competence between Poecilia reticulata and Aplocheilus panchax and determined the both fish has predation behavior for mosquito larvae.

Sarwar et al. (2015a and 2015b) found Gambusia affinis that can consume per day 100 to 300 Aedes mosquitoes larvae, Gambusia and guppy Poecilia eat less than 100 larvae. Pamplona (2006) applied practical measures with five inactive larvivorous species including Bettasplendens, Trichogastertrichopteros, Astyanaxfasciatus, Poecilia sphenops, and Poecilia reticulata to counter Aedes aegypti larval invasion in the Brazil. Similarly Seng et al. (2008) conducted study in which they described that villages in Cambodia had been seventy-nine percent decreases in $A$. aegypti larval epidemic as it was discovered and observed compared to monitoring and practical control practices of villages. A specifically targeted predator reflects substantial impending for consideration in the bio-monitoring and practical control practices of vector carrying mosquitoes. Still, in severe ecological conditions, predator scan just endure as long as their favored breathing eco-friendly environments and settings are dynamically existed, albeit difficult to achieve and sustain. However, predator's life cycle requires being well implemented or appropriate with the prerequisites demanded by prey. To control Aedes aegypti mosquitoes, defined as Gambusia, Poeciliidae and Poecilia are highly preferred predatory larvivorous fish. Poecilia can survive on limited availability of food and has breeding potential in confined pits and open wells and small size vessels. Gambusia can survive in large size water pond for long duration because it feeds on high availability of zooplankton (Ghosh et al., 2011).

Hora and Mukherjee (1953) conducted a study on the indication of Indian clean aquatic fishes, with depicting of particular families in addition to observations on the comparative efficacy of the actual predatory carnivorous fishes of India. Chandra et al. (2008) reported on the carnivorous Colisalalia mosquito larval feeding habitat found in both still and running waters. C. fasciatus a larvivorous culture procedure appropriate for exposed water surface exclusively in rice fields for monitoring and regulation practical practices of such larvivorous parasites, locally existing available and accessible local, indigenous and native fish composed as of pebble pits of Allahabad and Shahjahan-pur district. Populations of local Mesocyclops spp.were comprised in precisely designed municipality, communal and metropolis based monitoring and control practical practices plans maintained through Micronecta aquatic microbes in addition to fish for monitoring and practical control practices of dengue disease in Vietnam (Nam et al., 2000). In coastal village in Taiwan on integrated monitoring and control practical practices of $A$. aegypti and A.albopictus utilizing G. affinis, Tilapia mossambica, $P$. reticulata, and Sarotherodonniloticus drinking water containers and these fish spp. were far along substituted with Cyprinuscarassius as per their relaxed adaptability and accessibility to native ecological and environmental settings (Wang et al., 2000). From 1980s onward villages in Chinese coastal provinces, Chinese catfish was also practical practices applied in the direction ofmonitoring and practical control practices of $A$. aegypti and A.albopictus larval breeding potential in order to tackle dengue fever epidemic which happened to cause this disease in fish and respective victims ( $\mathrm{Wu}$ et al., 2016). In Thailand, effective implementation of practical control practices over $A$. aegypti and A.albopictus were by using fish covered water storage tanks (Phuanukoonnon et al., 2005).

\section{Dragonfly nymph}

Dragonfly nymph breeds in fresh aquatic reserves and respective habitat. Larvaecidal competence of nymph of dragonfly as water centered predators that are examined at research laboratory level. Dragonfly's nymphs consume as a minimum around of fifty larvae of mosquitoes per hour. Because they monitor and furish control practices of diseases which spread through mosquito and conserving marine feature and have microbe such as phytoplankton, 
zooplankton etc (Singh., 2003). Males Rhodothemis rufa showed higher rate of predation larvae of Culex quinquefasciatu was higher than that of females larvae (Chandra et al., 2016). Neurothemis fluctuans and Orthetrum sabina utilized Aedes aegypti larvae as most preferred feeding option and Culex quinquefasciatus prey the Orthetrum chrysis consumed more in contrast to other species (Norma and Saleeza et al., 2014).

Therefore, dragonflies are benign for humanoid consumption along with their economic viability. Under the alternative strategy of dengue and malaria monitoring and control practical practices by means of ecological and ecological enhancement practices, crucial significance is given on the way to anti larval procedures (Shad and Andrew, 2013). Nymphs capture mosquito larva by the modified labium, which pass into a structure known as mask. Though, during catching prey mask is tossed out and stretched with implausible rapidity and the prey engrossed with the hook is trapped into the buckle-cavity, correspondingly. At rest the labrum is folded over the jaws but can be extended to collect prey within a fraction of a second. Preference of food of Dragonfly nymph includes mosquito larvae and pupae, nymphs of their own species, chironomid larvae, small tadpoles in laboratory condition (Chandra et al., 2006; Chatterjee et al., 2007).

\section{Frogs}

Recent accompanied research on using of mosquito bugs and tadpoles in controlling mosquitoes has grown interest. It is defined as the harmful outcome on respectively other's growth and subsistence, which was anticipated to be outstanding to positive physiological, chemical and biological aspects (Sarwar, 2015b). Mokany and Shine (2002) study reported that a considerable deduction and observed decline in survival rates of Culex quinquefasciatus and Aedes australis larvae in laboratory experiments and while in ground, reduction was observed and documented in ovi-status of female mosquito in the tadpoles of the Limnodynastes peronii and Crinia signifera that utilized mosquitoes larvae as most preferred feeding option. Marian et al, (1983) also examined and found that $R$. tigrina tadpoles preference for pupal stages. Consequently, existence of supplementary microbes that influence instantaneous predator-prey compression on diverse phases of mosquito emergent that remained undeveloped and immature, that will be further operational in regards to monitoring and practical control practices and extent. Various larvae released after predation and transform to pupal phases; in such circumstances existence of $R$. tigrina tadpoles have a potential role to exert immediate stress on pupal phases. In
1974, Spielman and Sullivan examined and described on the basis of $C x$. pipiens and Hyla septentrionalis tadpoles larvae which consumed on mosquito larvae and they detected and consequently noticed decline of population of $C x$. Pipens along with Hyla sp. in sample field as per particular prey preference. In 2006, Kumar and Hwange demonstrated that establishment of bio-control agents by the interactions of prey-predator community, if the conditions when arise predator shows negative consumptive effect in the environment, as result decrease inter-and intra-competition particularly augmented quantities of marked and targeted types. Therefore, net impact evaluations accessed from the research work on the consideration over sample frog population in addition to prey and predator that is practically operational through the process of manipulation and prediction of success rate for its practical application in the research work of vector monitoring and practical control practices. Environmental principles of bio manipulation in certain areas may be applied for such vector monitoring and control practical practices aimed at pointing, management and controlling strategies (Raghavendra et al., 2008).

\section{Copepods}

Copepods biological practical control agents. Copepods are basically little crustaceans that are used as and the live in aquatic habitats and eats larvae of mosquito confined in artificial containers to control mosquito larvae of public health significance (Kay et al., 2002; Soumare et al., 2011; Lazaro et al., 2015). In Thailand different copepods like Mesocyclops thermocyclopoides, Mesocyclops guangxiensis, Mesocyclops aspericornis, have been detected and noticed as operative bio-monitoring and practical control measures for Aedes aegypti larvae (Kosiyachinda et al., 2003). Mosquito larvae are key functional component of the food chain and are the lists of invertebrate predators for food which depend upon mosquito larvae in aquatic ecosystems. In recent study for the as intervention measures of Culex pipiens and Aedes albopictus in Italy Macrocyclops albidus were applied and found that mosquito population was under control but The main problem depicting survival of copepods is the accumulation of hypoxia due to less dissolved oxygen in water and toxic metals residues in the water. Only 1st and 2nd instar Copepods feed on the mosquito larvae and average consumption up to 35 larvae per day (Veronesi et al., 2015).

\section{Turtle}

Turtles belongs to aquatic predators and consume a variety of creatures comprising larvae of different mosquitoes. Borjas et al. (1993) have worked on Red eared slider turtles reported that turtle overlooked $1^{\text {st }}$ instars but consumed to approximately about on $2^{\text {nd }}$ instars, and finally preyed 
particularly on $3^{\text {rd }}$ and $4^{\text {th }}$ instars larva and pupa. The turtles regularly consumed approximately one-thousand larvae per hour depending on availability of mosquito's larva. Still, turtles practices have been applied in inaccessible aquatic tanks for example aquatic ponds, seasonal storm water catch basins and providing supplementary food when needed (Marten, 2007).

\section{Entomopathogenic bacilli}

At present, Bacillus thuringiensis varisraelensis and Bacillus sphaericus, merely two types of entomo-pathogenic bacilli as Coelomomyces, Culicinomyces and Lagenidium, are environmental and ecological safe practices applied in mosquitos control programs (Scholte et al., 2004; Darbro et al., 2011; Blanford et al., 2012). Entomo-pathogenic bacilli has great toxicant efficacy against and in contradiction of marked and targeted organisms and easy development on industrial scale. By simple integration into monitoring and vectors control programs involving municipality, community and metropolis participation make thuringiensis Varisraelensis and Bacillus sphaericus possibly the utmost operational and ecological controlling species. The insecticidal control activity of entomo-pathogenic bacilli based on the production of proteinaceous paraspora secreting crystalline mosquito-toxic proteins have been reported (Gammon et al., 2006; Luz et al., 2007).

\section{Bacillus thuringiensis israelensis Bti}

Currently Bacillus thuringiensis israelensis Bti isolated from soil effective to control larvae (Anderson et al.,2011; Tan et al.,2012; Wilson et al., 2015). Bti is more sensitive to water quality parameters especially chemical oxygen of water and light intensity effect like UV radiation emission (Silapanuntakul et al., 1983). Bacillus thuringiensis israelensis Bti development of protein cytolytic toxins that kill mosquitoes larvae at binding site on glycoprotein absorbers existed on border of midgut larval brush (Bravo et al., 2007; Manceva et al., 2005; Stalinski et al., 2016). In a recent study, Harwood et al. (2015) revealed that Bacillus thuringiensisisraelensis applied in granular form and showed higher mortality rates in tree-hole habitats and testing containers.

\section{Bacillus sphaericus}

B. sphaericus has less UV sensitivity and polluted water conditions (Gammon et al., 2006; Sougoufara et al., 2017). This bacterial species has a potential to be used as identifier as per its plump spore positioned terminally in a puffy sporangium. Various researchers described cytotoxins enhance toxicity of Bacillus sphaericus by synergistic effect of Bacillus thuringiensis var. israelensis at gene level (Wirth et al., 2000, 2001; Berry et al., 2002; Becker, 2003; Poopathi and Abidha, 2010; Silva-Filha., 2017).

In Kumasi Metropolis, Ghana recent study described that in the Bacillus thuringiensis var. israelensis minor dose of 0.2 $\mathrm{kg}$ / ha was effective against mosquito larvae, thus providing a viable option for managing vector mosquitoes (Nartey et al., 2013). Monnerat et al. (2004) observed that Bacillus sphaericus separates yielded protein contaminants mentioned as the insecticidal chemicals Methotrexate and molecular weight is approximately one-hundred $\mathrm{kDA}$ and and immune system suppressant did not cause hazard in environment. The tablet forms of Bacillus thuringiensis or Bacillus sphaericus substantially contaminated through gamma rays to stop adulteration of eating aquatic bodies with microorganisms, is magnificently viable practice that used to be applied, intended for monitoring and practical control in mosquitoes breeding container to control such as Ades aegypti in high risk areas (Mahilum et al., 2005).

\section{Conclusion}

Mosquitoes are documented for community health, nuisance problem, economically reducing real estate values of country, related business interests and adversely affect tourism. Research of imitation, preparations of pesticides, and usage reported ecologically destructive and environmentally unviable in different regions of the globe. The failure of traditional vector control operations observed from side to side biochemical pesticides rehabilitated concentration in biotic monitoring and practical control practices. An alternative monitoring and practical control measure for the eradication and monitoring and control practices of mosquitoes at larval level by the use of a judicious bio-content including their eco-friendly control techniques are utmost needed for monitoring and control for mosquitoes at larval. In bio-control measures to monitoring and control practical practices contexts predatory larvivorous fish, dragonfly nymph, frogs, copepods, turtle can be used. Entomo-pathogenic bacilli, Bacillus thuringiensism israelensis and Bacillus sphaericus used as predator species, which are specifically used in advancement for mosquito control in regards to lessen the ecologically destructive outcomes such as bio-magnification etc. Moreover, the company of diverse prey and predator associations observed in the ecological surroundings to measure the viability of usage of a predator as bio-control agents for vector monitoring, practical control practices and proper management. To eradicate mosquitoes it is suggested that extinction of natural enemies of mosquitoes such larvivorous fish, dragonfly nymph, frogs, copepods, turtle should be 
prohibited and thus sustain these species population in aquatic system of natural and artificial water bodies of particular region of any country.

\section{References}

Aditya G, Pal S, Saha N and Saha GK (2012), Efficacy of indigenous larvivorous fishes against Culex quinquefasciatus in the presence of alternative prey: implications for biological control, J Vector Borne Dis. 1: 217-225.

Anderson JF, Ferrandino FJ, Dingman DW, Main AJ, Andreadis TG and Becnel JJ (2011), Control of mosquitoes in catch basins in Connecticut with Bacillus thuringiensis israelensis, Bacillus sphaericus, and spinosad, Journal of the American Mosquito Control Association 27(1): 45-55. DOI. org/10. 2987/10-6079.1

Atique S, Abdul SS, Hsu CY and Chuang TW (2016), Meteorological influences on dengue transmission in Pakistan, Asian Pacific journal of tropical medicine 9(10): 954-961. DOI. org/10.1016/j.apjtm.2016.07.033

Bandyopadhyay S and Skoufias E (2015), Rainfall variability, occupational choice, and welfare in rural Bangladesh, Review of Economics of the Household 13(3): 589-634. DOI.org/10.1596/1813-9450-6134

Becker N (2003), Ice granules containing endotoxins of microbial control agents for the control of mosquito larvae - a new formulation technique, J. Am. Mosq. Control Assoc. 19: 63-66.

Berry C, O'Neil S, Ben-Dov E, Jones AF, Murphy L, Quail MA and Parkhill J (2002), Complete sequence and organization of pBtoxis, the toxin-coding plasmid of Bacillus thuringiensis subsp. israelensis, Applied and environmental microbiology 68(10): 5082-5095. DOI: 10.1128/AEM.68.10.5082-5095.2002

Blanford S, Jenkins NE, Read AF and Thomas MB (2012), Evaluating the lethal and pre-lethal effects of a range of fungi against adult Anopheles stephensi mosquitoes, Malaria journal 11(1): 365. DOI.org/10.1186/ 1475-2875-11-365

Borjas G, Marten GG, Fernandez E and Portillo H (1993), Juvenile turtles for mosquito control in water storage tanks, Journal of medical entomology 30(5): 943-946. DOI.org/10.1093/jmedent/30.5.943
Bouzid M, Brainard J, Hooper L and Hunter PR (2016), Public health interventions for Aedes control in the time of Zikavirus - a meta-review on effectiveness of vector control strategies, PLoS Neglected Tropical Diseases 10(12): e0005176. DOI.org/10.1371/ journal.pntd.0005176

Bravo A, Gill SS and Soberón M (2007), Mode of action of Bacillus thuringiensis Cry and Cyt toxins and their potential for insect control, Toxicon 49(4): 423-435. DOI.org/10.1016/j.toxicon.2006.11.022

Chandra G, Bhattacharjee I, Chatterjee SN and Ghosh A (2008), Mosquito control by larvivorous fish, Indian Journal of Medical Research 127(1): 13.

Chandra G, Chatterjee SN and Ghosh A (2006), Role of dragonfly (brachytronpratense) nymph as a biocontrol agent of larval mosquitoes, Buletin Penelitian Kesehatan 34(4).

Chandra G, Mondal B, Bandyopadhyay S and Ghosh A (2016), Sex-specific functional responses of dragonfly naiads Rhodothemis rufa on Culex quinquefasciatus larvae in laboratory bioassay, International Journal of Pest Management 62(2): 135-139.

Chatterjee SN, Ghosh A and Chandra G (2007), Eco-friendly control of mosquito larvae by Brachytron pratense nymph, Journal of environmental health 69(8): 44.

Chaudhry M, Ahmad S, Rashid HB and Din IU (2017), Dengue Epidemic in Postconflict Swat District, Khyber Pakhtunkhwa, Pakistan, 2013, The American journal of tropical medicine and hygiene 96(4), 899-902. DOI: https://doi.org/10.4269/ajtmh.16-0608

Darbro JM, Graham RI, Kay BH, Ryan PA and Thomas MB (2011), Evaluation of entomopathogenic fungi as potential biological control agents of the dengue mosquito, Aedes aegypti (Diptera: Culicidae), Biocontrol science and technology 21(9): 1027-1047.

Diallo M, Dia I, Diallo D, Diagne CT, Ba Y and Yactayo S (2016), Perspectives and Challenges in Entomological Risk Assessment and Vector Control of Chikungunya, The Journal of infectious diseases 214(suppl_5): S459-S465.

Dieng H, Hassan AA, Satho T, Miake F, Salmah MRC and Abu Bakar S (2011), Insecticide susceptibility of the dengue vector Aedes aegypti (Diptera: Culicidae) in 
Makkah City, Saudi Arabia, Asian Pacific J Tropical Dis. 1(2): 94-99.

Fatima SH. Atif S, Rasheed SB, Zaidi F and Hussain E (2016), Species Distribution Modelling of Aedes aegypti in two dengue-endemic regions of Pakistan, Tropical Medicine \& International Health 21(3): 427-436.

Gammon K, Jones GW, Hope SJ, de Oliveira CM, Regis L, Filha MHNS and Berry C (2006), Conjugal transfer of a toxin-coding megaplasmid from Bacillus thuringiensis subsp. israelensis to mosquitocidal strains of Bacillus sphaericus, Applied and environmental microbiology 72(3): 1766-1770.

George LS, Aswathy S, Paul N and Leelamoni K (2017), Community based interventional study on dengue awareness and vector control in a rural population in Ernakulam, Kerala, International Journal of Community Medicine And Public Health 4(4): 962-967. DOI: http://dx.doi.org/ 10.18203/ 23946040.ijcmph20170984

Ghosh A, Bhattacharjee I, Ganguly M, Mondal S and Chandra G (2004), Efficacy of some common aquarium fishes as biocontrol agent of preadult mosquitoes, Buletin Penelitian Kesehatan 32(4 Des).

Ghosh SK, Chakaravarthy P, Panch SR, Krishnappa P, Tiwari S, Ojha VP and Dash AP (2011), Comparative efficacy of two poeciliid fish in indoor cement tanks against chikungunya vector Aedes aegypti in villages in Karnataka, India, BMC Public Health 11(1): 599.

Gupta S and Banerjee S (2013), Comparative assessment of mosquito biocontrol efficiency between Guppy (Poecilia reticulata) and Panchax minnow Aplocheilus panchax), Biosci. Discov 4: 89-95.

Hafeez S, Amin M and Munir BA (2017), Spatial mapping of temporal risk to improve prevention measures: A case study of dengue epidemic in Lahore, Spatial and Spatio-temporal Epidemiology 21: 77-85. DOI.org/10.1016/j.sste.2017.04.001

Harinder S and Sukhmeet M (2014), A study of larval indices of Aedes and the risk for dengue outbreak, Sch. Acad. J. Biosci. 2(8): 544-547.

Harwood JF, Farooq M, Turnwall BT and Richardson AG (2015), Evaluating liquid and granular Bacillus thuringiensis var. israelensis broadcast applications for controlling vectors of dengue and chikungunya viruses in artificial containers and tree holes, Journal of medical entomology 52(4): 663-671.

Hati AK and Ghosh SM (1965), Laboratory studies on the predacious habits of the dragon fly nymph, Bulletin of the Calcutta School of Tropical Medicine 13(2): 61.

Hora SL and Mukherjee D (1953), Manager of publication, Delhi, India, p 213.

Huang YJS, Higgs S and Vanlandingham DL (2017), Biological control strategies for mosquito vectors of arboviruses, Insects 8(1): 21. DOI.10.3390/insects 8010021

Kay BH, Nam VS, Van Tien, T, Yen NT, Phong TV, Diep VTB and Aaskov JG (2002), Control of Aedes vectors of dengue in three provinces of Vietnam by use of Mesocyclops (Copepoda) and community-based methods validated by entomologic, clinical, and serological surveillance, The American journal of tropical medicine and hygiene 66(1): 40-48.

Kosiyachinda P, Bhumiratana A and Kittayapong P (2003) Enhancement of the efficacy of a combination of Mesocyclops aspericornis and Bacillus thuringiensis var. israelensis by community-based products in controlling Aedes aegypti larvae in Thailand, The American journal of tropical medicine and hygiene 69(2): 206-212.

Kumar R and Hwang JS (2006), Larvicidal efficiency of aquatic predators: A perspective for mosquito biocontrol, Zoological Studies 45: 447-466.

Lacey LA (2007), Bacillus thuringiensis serovariety israelensis and Bacillus sphaericus for mosquito control, Journal of the American Mosquito Control Association 23(sp2): 133-163.

Lazaro A, Han WW, Manrique-Saide P, George L, Velayudhan R, Toledo J and Horstick O (2015), Community effectiveness of copepods for dengue vector control: systematic review, Tropical Medicine \& International Health 20(6): 685-706.

Luz C, Tai MHH, Santos AH, Rocha LFN, Albernaz DAS and Silva HHG (2007), Ovicidal activity of entomopathogenic hyphomycetes on Aedes aegypti (Diptera: Culicidae) under laboratory conditions, 
Journal of medical entomology 44(5): 799-804. DOI.org/10.1603/0022-2585(2007)44[799:OAOEHO ]2.0.CO;2

Mahilum M, Madon M, Storch V, Ludwig M and Becker N (2005), Evaluation of the present dengue situation and control tools against Aedes aegypti in Cebu City, Philippines, J. Vector Ecol. 30: 277-283.

Malik A, Yasar A, Tabinda AB, Zaheer IE, Malik K, Batool A, and Mahfooz Y (2017), Assessing spatio-temporal trend of vector breeding and dengue fever incidence in association with meteorological conditions, Environmental monitoring and assessment 189(4): 189.

Manceva SD, Pusztai M, Russo PS and Butko P (2005), A detergent similarly and correspondingly mechanism of action of the cytolytic toxin Cyt1A from Bacillus thuringiensis var. israelensis, Biochemistry 44: 589-597.

Manilal A, Thajuddin N, Selvin J, Idhayadhulla A, Kumar RS and Sujith S (2011), In Vitro Mosquito Larvicidal Activity of Marine Algae against the Human Vectors, Culex quinquefasciatus (Say) and Aedes aegypti (Linnaeus) (Diptera: Culicidae), Inter J Zoological Research 7(3): 272-278.

Marian MP, Christopher MSM, Selvaraj AM and Pandian TJ (1983), Studies on predation of the mosquito Culexfatigans by Ranatigrina tadpoles, Hydrobiologia 106: 59-63.

Marten GG (2007), Biorational Control of Mosquitoes, American Mosquito Control Association Bulletin, Ed. TG Floore, p 7.

Martinez-Ibarra JA, Guillén YG, Arredondo-Jiménez JI and Rodríguez-López MH (2002), Indigenous fish species for the control of Aedes aegypti in water storage tanks in Southern Mexico, Biocontrol 47: 481-486.

Mokany A and Shine R (2002), Pond attributes influence competitive interactions between tadpoles and mosquito larvae, Austral Ecol. 27: 396-404.

Monnerat R, Silva SF, Dias DS, Martins ES, Praca LB, Jones GW, Soares CM, de Souza Dias JMC and Berry C (2004), Screening of Brazilian Bacillus sphaericus strains for high toxicity against Culex quinquefasciatus and Aedes aegypti, J. Appl. Entomol. 128: 469-473.
Nam VS, Yen NT, Holynska M, Reid JW and Kay BH (2000), National progress in dengue vector control in Vietnam: survey for Mesocyclops (Copepoda), Micronecta (Corixidae), and fish as biological control agents, Am. J. Trop. Med. Hyg. 62(1): 5-10. DOI: https://doi.org/10.4269/ajtmh.2000.62.5

Naqvi SAA, Kazmi SJH, Shaikh S and Akram M (2015), Evaluation of prevalence patterns of dengue fever in Lahore District through geo-spatial techniques, Journal of Basic \& Applied Sciences 11: 20.

Nartey R, Owusu-Dabo E, Kruppa T, Baffour-Awuah S, Annan A, Oppong S and Obiri-Danso K (2013), Use of Bacillus thuringiensis var israelensis as a viable option in an Integrated Malaria Vector Control Programme in the Kumasi Metropolis, Ghana, Parasites \& vectors 6(1): 116. DOI.org/10.1186/1756-3305-6-116

Norma R Y and Saleeza SNR (2014), Eco-friendly Control of Three Common Mosquito Larvae Species by Odonata Nymphs In: Basic and Applied Aspects of Biopesticides, Springer India, pp 235-243.

Pamplona LGC (2006), Potencial de cincoespe' cies de peixecomome'todo de controlebiolo' gico de larvas de Aedesaegypti, emcondic, $\mathrm{o}^{\sim}$ es de laborato' rio, no Ceara, MS Thesis, Federal University of Ceara', Ceara', Brazil.

Phuanukoonnon S, Mueller I and Bryan JH (2005), Effectiveness of dengue control practices in household water containers in Northeast Thailand, Trop. Med. Int. Health 10: 755-763.

Poopathi S and Abidha S (2010), Mosquitocidal bacterial toxins (Bacillus sphaericus and B. thuringiensis serovar israelensis): Mode of action, cytopathological effects and mechanism of resistance, Journal of Physiology and Pathophysiology 1(3): 22-38.

Qadri SS, Tariq RM and Ahmad I (2007), Dengue Kee Wapsi. Global Science, pp 21-26.

Raghavendra K, Sharma P and Dash AP (2008), Biological control of mosquito populations through frogs: opportunities \& constrains, Indian Journal of Medical Research 128(1): 22.

Ritchie SA (2005), Evolution of dengue control strategies in North Queensland, Australia, Arborvirus Res. Australia 9: 324-330. 
Ritchie SA, Rapley LP and Benjamin S (2010), Bacillus thuringiensis var. israelensis (Bti) Provides Residual Control of Aedes aegypti in Small Containers, Am. J. Trop. Med. Hyg. 82: 1053-1059. DOI.org/ 10.4269/ajtmh.2010.09-0603

Santos J and Meneses BM (2017), An integrated approach for the assessment of the Aedes aegypti and Aedes albopictus global spatial distribution, and determination of the zones susceptible to the development of Zika virus, Acta tropica 168: 80-90. DOI.org/10.1016/j.actatropica.2017.01.015

Sarwar M (2015a), Control of dengue carrier Aedes mosquitoes (Diptera: Culicidae) larvae by larvivorous fishes and putting it into practice within water bodies, International Journal of Preventive Medicine Research 1(4): 232-237.

Sarwar M (2015b), Controlling dengue spreading Aedes mosquitoes (Diptera: Culicidae) using ecological services by frogs, toads and tadpoles (Anura) as predators, American Journal of Clinical Neurology and Neurosurgery 1(1): 18-24.

Scholte EJ, Knols BG, Samson RA and Takken W (2004), Entomopathogenic fungi for mosquito control: a review, Journal of Insect Science 4(1). DOI.org/ $10.1093 /$ jis/4.1.19

Seng CM, Setha T, Nealon J, Socheat D, Chantha N and Nathan MB (2008), Community-based use of the larvivorous fish Poecilia reticulata to control the dengue vector Aedes aegypti in domestic water storage containers in rural Cambodia, Journal of Vector Ecology 33(1): 139-144. DOI.org/10.3376/ 10811710(2008)33[139:CUOTLF]2.0.CO;2

Shad A and Andrew J (2013), Original Research Article A Study on the Predatory Potency of Dragonfly, Bradinopyga geminata Nymphs over the Immature Stages of the Filarial Vector, Culex quinquefasciatus Say, Int. J. Curr. Microbiol. App. Sci. 2(4): 172-182.

Silapanuntakul S, Pantuwatana S, Bhumiratana A and Charoensiri K (1983), The comparative persistence of toxicity of Bacillus sphaericus strain 1593 and Bacillus thuringiensis serotype $\mathrm{H}-14$ against mosquito larvae in different kinds of environments, $J$. Invertebr. Pathol 42(3): 387-392. DOI.org/10.1016/ 0022-2011 (83)90179-9
Silva-Filha MHNL (2017), Resistance of Mosquitoes to Entomopathogenic Bacterial-Based Larvicides: Current Status and Strategies for Management. In: Bacillus thuringiensis and Lysinibacillus sphaericus, pp 239-257.

Singh RK, Dhiman RC and Singh SP (2003), Laboratory studies on the predatory potential of dragon-fly nymphs on mosquito larvae, The Journal of communicable diseases 35(2): 96-101.

Sougoufara S, Doucouré S, Sembéne PMB, Harry M and Sokhna C (2017), Challenges for malaria vector control in sub-Saharan Africa: Resistance and behavioral adaptations in Anopheles populations, Journal of Vector Borne Diseases 54(1): 4.

Soumare MKF and Cilek, JE (2011), The effectiveness of Mesocyclops longisetus (Copepoda) for the control of container-inhabiting mosquitoes in residential environments, Journal of the American Mosquito Control Association 27(4): 376-383.

Spielman A and Sullivan JJ (1974), Predation on peridomestic mosquitoes by Hylid tadpoles on Grand Bahama Island, Am. J. Trop. Med.Hyg. 23: 704-9.

Stalinski R, Laporte F, Després L and Tetreau G (2016), Alkaline phosphatases are involved in the response of Aedes aegypti larvae to intoxication with Bacillus thuringiensis subsp. israelensis Cry toxins, Environmental microbiology 18(3): 1022-1036.

Sutherst RW (2004), Global change and human vulnerability to vector-borne diseases, Clinical Microbiology Reviews 17(1): 136-173. DOI: 10.1128/CMR. 17.1.136-173.2004

Tan AWA, Loke SR, Benjamin S, Lee HL, Chooi KH and Sofian-Azirun M (2012), Spray application of Bacillus thuringiensis israelensis (Bti strain AM65-52) against Aedes aegypti (L.) and Ae. albopictus Skuse populations and impact on dengue transmission in a dengue endemic residential site in Malaysia, Southeast Asian Journal of Tropical Medicine and Public Health 43(2): 296.

Tariq RM (2001), Where the mosquitoes Aedes, Anopheles \&Culex are breeding in Karachi, Sindh-Pakistan? Pakistan j. entomol. Karachi 16(1\&2): 15-18. 
Tariq RM and Qadri SS (2008), Levels of dengue fever virus control: the effectiveness and vastness of controlling power boundaries of these levels, Pakistan j. entomol. Karachi 23 (1\&2): 61-62.

Terbot JW, Nikbakhtzadeh MR and Foster WA (2015), Evaluation of Bacillus thuringiensis israelensis as a Control Agent for Adult Anopheles gambiae, Journal of the American Mosquito Control Association 31(3): 258-261. DOI.org/10.2987/moco-31-03-258-261.1

Thomas MB (2017), Biological control of human disease vectors: a perspective on challenges and opportunities, Bio Control 3: 1-9.

Veronesi R, Carrieri M, Maccagnani B, Maini S and Bellini R (2015), Macrocyclops albidus (Copepoda: cyclopidae) for the Biocontrol of Aedes albopictus and Culex pipiens in Italy, Journal of the American Mosquito Control Association 31(1): 32-43. DOI.org/10.2987/13-6381.1

Wang CH, Chang NT, Wu HH and Ho CM (2000), Integrated control of the Dengue vector Aedes aegypti in Liu-Chiu village, Ping-Tung County, Taiwan, $J$. Am. Mosq. Control Assoc. 16: 93-99.
Wilson AL, Boelaert M, Kleinschmidt I, Pinder M, Scott TW, Tusting LS and Lindsay SW (2015), Evidence-based vector control? Improving the quality of vector control trials, Trends in parasitology 31(8): 380-390.

Wirth MC, Delécluse A and Walton WE (2001), Cyt1Ab1 and Cyt2Ba1 from Bacillus thuringiensis subsp. medellin and B. thuringiensis subsp. israelensis synergize Bacillus sphaericus against Aedesaegypti and resistant Culexquinquefasciatus (Dipetera: Culicidae), Appl. Environ. Microbiol. 67: 3280-3284. DOI: 10.1128/AEM.67.7.3280-3284.2001

Wirth MC, Federici, BA and Walton WE (2000), Cyt1A from Bacillus thuringiensis synergizes activity of Bacillus sphaericus against Aedes aegypti (Diptera: Culicidae), Appl. Environ. Microbiol. 66: 1093-1097.

Wu X, Lu Y, Zhou S, Chen L and Xu B (2016), Impact of climate change on human infectious diseases: empirical evidence and human adaptation, Environment International 86: 14-23. DOI.org/ 10.1016/j.envint.2015.09.007 